SCADidoc

\section{Occurence Of Number Of Canals In Permanent Mandibular First Molar In South Indian Population - A Retrospective Analysis}

International Journal of Dentistry and Oral Science (IJDOS) ISSN: $2377-8075$

Research Article

Swarna. S.K ${ }^{1}$, Pradeep. S $2^{2}$, S. Haripriya ${ }^{3}$

${ }^{1}$ Saveetha Dental College and hospitals Saveetha University of Medical And Technical Science (SIMATS) Saveetha University. Chennai-600077, India. ${ }^{2}$ Reader, Department of Conservative Dentistry and Endodontics, Saveetha Dental College and Hospitals Saveetha University of Medical And Technical Science(SIMATS) Saveetha University. Chennai-600077, India.

${ }^{3}$ Senior Lecturer, Department of Conservative Dentistry and Endodontics, Saveetha Dental College and Hospitals, Saveetha Institute of Medical and Technical Sciences,Saveetha University, Chennai 600 077, Tamil Nadu, India.

\title{
Abstract
}

The mandibular first molar has a wide variety of root canal configurations. Adequate knowledge of the root canal system is necessary to achieve optimum disinfection and hence successful outcomes in Endodontic therapy. The aim of this Retrospective study is to evaluate the occurrence of number of canals in permanent mandibular first molars by analyzing postoperative periapical radiographs. A total of 1300 case sheets of root canal treated mandibular first molars were reviewed and data extraction regarding age, gender and number of canals were done. Data was tabulated in Excel sheets and analyzed using SPSS software. The results showed that out of 1300 teeth, 712 were male and 588 female patients. Out of 712 male patients, 452 $(63.4 \%)$ had 3 canals and $244(34.2 \%)$ had 4 canals. Out of 588 female patients, $396(67.3 \%)$ had 3 canals and $173(29.4 \%)$ had 4 canals. No significant difference was seen between the number of canals amongst gender. The knowledge of root canal anatomy reduces the chances of missing a canal during root canal treatment. Also various anatomical intricacies of the root canal system such as fins, isthmuses and C- shaped canals are commonly seen in mandibular molars. Sufficient disinfection of the entire root canal system by use of irrigant activation techniques and intra canal medicaments, will help in achieving long term success of root canal treatment.

Keywords: Canal Configuration; Canal Variations; Mandibular First Molar; Number Of Canals; Root Canal Treatment.

\section{Introduction}

The main goal of endodontic therapy is to achieve adequate cleaning, shaping and disinfection that would allow for three - dimensional obturation of the root canal system [34]. Irrigant activation plays a major role in achieving disinfection in canal intricacies such as fins, isthmuses and c shaped canals [27]. Knowledge of root canal configuration is a critical factor in aiding clinician to locate the canals, follow the root canal curvatures and to effectively disinfect the root canal system without violating the original root canal anatomy.

The mandibular first molar has a wide variety of root canal configuration [36]. Variations in the morphology of dental pulp are caused by genetic and environmental influences and the clinicians should be aware of the frequency of racially determined forms [10]. The occurrence of middle mesial canal in the mesial root of mandibular first molars and presence of additional distal canal should be checked during root canal treatment. Incase of lower second molars, there is a higher possibility of getting a C- shaped canal [9].

The morphology and buccolingual width of the mesial root of permanent mandibular first molar has numerous connecting pulpal passages $[4,7]$. Root canal morphology and configuration have been classified by Wein et al [42], Pineda and Kuttler [25], (Pineda and Kuttler, 1972), and Vertucci [39]. Studies on root canal anatomy of mandibular first molar have been performed in several populations [23].

\section{*Corresponding Author}

Pradeep. S,

Reader, Department of Conservative Dentistry and Endodontics, Saveetha Dental College and Hospitals Saveetha University of Medical And Technical Science(SIMATS) Saveetha University. Chennai-600077, India.

Tel: +919710404482

Email Id: pradeeps@saveetha.com

Received: December 02, 2020

Accepted: January 21, 2021

Published: February 27, 2021

Citation: Swarna. S.K, Pradeep. S, S. Haripriya. Occurence Of Number Of Canals In Permanent Mandibular First Molar In South Indian Population - A Retrospective Analysis. Int J Dentistry Oral Sci. 2021;08(02):1797-1800. doi: http://dx.doi.org/10.19070/2377-8075-21000356

Copyright: Pradeep. $\mathbf{S}^{\circ}$ 2021. This is an open-access article distributed under the terms of the Creative Commons Attribution License, which permits unrestricted use, distribution and reproduction in any medium, provided the original author and source are credited. 
This study was done to evaluate the occurrence of number of canals in mandibular first molars and to derive an association between gender and number of canals in a South Indian population by evaluating postoperative periapical radiographs.

\section{Materials and Methods}

This Retrospective study was conducted at Saveetha Dental College in 2020. Case sheets were analyzed from June 2019 to April 2020. A total of 1300 case sheets of root canal treated mandibular first molars were reviewed and analyzed. The case sheets were cross-verified by another examiner to avoid missing any data. The age, gender and number of canals were checked by date evaluation, photographic as well as periapical radiographic evaluation.

Inclusion criteria were patients in age group of 18-65 years of age who underwent root canal treatment for mandibular first molars. Exclusion criteria included teeth with developmental anomalies and any defectively formed or calcified teeth.

Sampling bias was minimized by verifying the photographs and radiographs by another reviewer. After verification of dental hospital management system records of all patients, the data such as number of canals in mandibular first molar, age and gender of patient, were tabulated. Incomplete data or radiographs which are not of adequate diagnostic value were excluded from the study to achieve better accuracy of results. All the cases were analysed with intraoral periapical radiographs. In cases of predilection of extra canals or aberrant anatomy, CBCT had been included in patient data which was also screened to verify the extra canals.

\section{Statistical Analysis}

Statistical analysis was performed using SPSS software. Association of age and gender with number of canals were calculated using Descriptive statistics. The periapical radiographs were selected using convenience sampling. The independent variables were assigned as gender and the dependent variable was root canal treated mandibular first molars. The data analysis performed was associative and descriptive using SPSS software (SPSS version 23.0, SPSS, Chicago, IL, USA). The values greater than 0.05 were insignificant.

\section{Results and Discussion}

A total of 1300 mandibular first molars were evaluated, out of which $712(54.7 \%)$ belonged to male and 588 (45.2\%) belonged to female patients. The number of canals, most commonly observed in both male and female patients was 3 followed by 4 canals. Out of 712 male patients, $452(63.4 \%)$ had 3 canals and $244(34.2 \%)$ had 4 canals. Out of 588 female patients, $396(67.3 \%)$ had 3 canals and $173(29.4 \%$ ) had 4 canals (Table 1) (Fig 1). There was no significant difference seen between gender and number of canals in permanent mandibular first molar. Association between gender and number of canals was not statistically significant, $(p>0.05)$ according to the Chi square test (Table 2).

Figure 1. Bar graph depicting the association between gender of patient and the number of canals in permanent mandibular first molar. ( $\mathrm{X}$ axis: Gender, $Y$ axis: Number of cases; Blue: 1 canal, Red: 2 canals, Green: 3 canals, Orange: 4 canals, Yellow: 5 canals, Cyan- 6 canals. 3 canals - more common in mandibular first molars followed by 4 canals in both genders. (Chi square test; $p$ value $=.272$ - not significant)

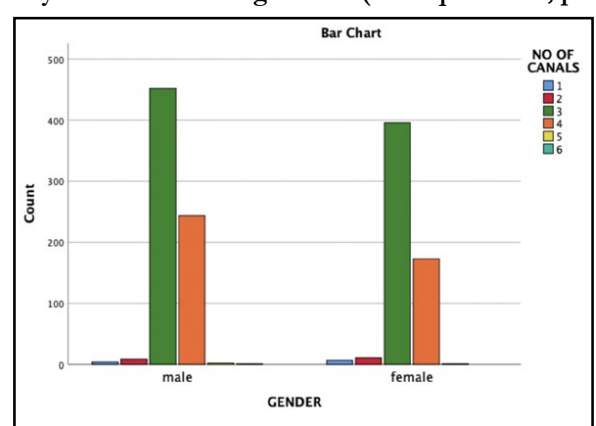

Table 1. Distribution of number of canals amongst Gender in Mandibular First Molar.

\begin{tabular}{|c|c|c|c|c|c|c|c|c|}
\hline \multicolumn{2}{|c|}{ No. of canals } & $\mathbf{1}$ & $\mathbf{2}$ & $\mathbf{3}$ & $\mathbf{4}$ & $\mathbf{5}$ & $\mathbf{6}$ & Total \\
\hline \multirow{2}{*}{ Gender } & Male & 4 & 9 & 452 & 244 & 2 & 1 & 712 \\
\cline { 2 - 9 } & Female & 7 & 11 & 396 & 173 & 1 & 0 & 588 \\
\hline \multirow{2}{*}{ Total } & & 11 & 20 & 848 & 417 & 3 & 1 & 1300 \\
\hline
\end{tabular}

Table 1- Shows canal distribution of permanent mandibular first molar, among male and female patients. On analysis, 452 male and 396 female patients had 3 canals, 244 male and 173 female patients had 4 canals.

Table 2. Association between gender and the canal variations in mandibular first molars.

\begin{tabular}{|c|c|c|c|}
\hline & Value & df & Asymptomatic Significance ( 2- sided) \\
\hline Pearson Chi- square & 6.369 & 5 & 0.272 \\
\hline Likelihood ratio & 6.758 & 5 & 0.239 \\
\hline Linear- by- linear Association & 5.824 & 1 & 0.016 \\
\hline No of valid cases & 1300 & & \\
\hline
\end{tabular}

In Table 2, statistical test (Chi square test) was done to find the association between gender and number of canals, which revealed ( $\mathrm{p}$ value $>0.05$ ) which was not statistically significant. 
Identifying and assessing the root canal configuration and its varied anatomy is the key to achieving success in adequate disinfection of the root canal system [13]. Calcifications or pulp stones are commonly observed in traumatised teeth or in teeth with mild constant irritation from bacterial byproducts [15].

Andreasen et al., studied the effects of luxation of permanent teeth due to trauma and concluded that ulp necrosis was found in $52 \%$ of teeth and this complication was significantly related to the type of luxation and stage of root development [1]. Avulsion is most commonly seen in anteriors, although history of trauma should be enquired incase of any calcifications in molar teeth [33]. Also, the incidence of dental caries is much higher in a person under dental trauma than a normal individual [12].

Remnants of pulp in the missed canals are primary causes of failure of root canal therapy [5]. Disease of pulp may be inflammatory or infectious [11]. The inflamed and infected pulp tissue should be removed completely to achieve long term success of root canal therapy [29]. Studies on internal and external anatomy of teeth have shown that complex anatomical variations may occur in all teeth $[5,32]$. Various irrigants with antimicrobial action and substantivity [22]. The irrigants have been studied for their interaction and effectiveness [35]. The cleaning and shaping should involve judicious dentin removal while removal of the smear layer [37]. The intracanal medicament such as calcium hydroxide helps in effective disinfection of the root canal system [17].

The post endodontic restoration also plays a decisive role in determining the longevity of the strategically important mandibular molar [18]. The choice of post endodontic restoration may be veneers or full coverage restoration in anteriors [31]. But in posterior teeth adhesive restorations done in ninja access preparations, but in cases of conventional access preparations, full coverage restorations are advised [2, 3]. Incase of class $\mathrm{V}$ cervical lesions, extra care should be taken in deciding the restorative material that seals the teeth completely avoiding microleakage [19].

The factors that play a key role in these variations include ethnicity, age, gender and study design [32]. Most of the root canal treated mandibular first molars falls in the age group of 18-30 years. This can be understood well by the fact that the mandibular first molar is one of the earliest permanent teeth to erupt in oral cavity [38]. Also, the erupting teeth are not fully mature and mineralized, which make them more prone to decay. The anatomical pits, fissure and developmental grooves also act as plaque retention areas and facilitate rapid caries progression in patients with poor dietary habits and with improper brushing habits $[16,21]$.

In our study, the maximum number of canals in both male and female patients was 3 followed by 4 . Contrary to our study done in South Indian population, Chourasia et al, had studied 150 Indian mandibular first molars, using in vitro technique and concluded a high incidence of 4 canals $(36 \%)$ and extra distal roots $(5.3 \%)$ revealing that there are more chances of 2 nd distal canal in Indian population [5].

Most literature described presence of 2 canals in mesial root [30]. although first evidence of independent third mesial canal with its own access orifice and apical foramen was described by Vertucci and William $[30,40]$. Indian population in our study demonstrates
2 toots in the mandibular first molar which is similar to most studies in our population [6]. In contrast, the Mongoloid population exhibited mandibular first molars with 3 roots with a 3:1 ratio when compared to Caucasians and African Americans [41]. This variation could be a genetically determined characteristic.

Retrospective observation of endodontically treated teeth by using two-dimensional periapical radiographs was found to be most common in vivo technique [23]. Although CBCT is highly efficient in complex anatomical situations, the periapical radiographs are mandatory, cost effective, lesser radiation exposure and are sufficient for routine dental procedures. CBCT is an effective tool for identifying extra canals and advised in cases of persistent radicular infections. The judicious use of CBCT following ALARA principle is advantageous to get maximum benefits with minimal exposure $[14,24]$.

Gulabivala et al., concluded that there was a high prevalence of three rooted mandibular first molars and C-shaped root/canals in mandibular second molars in Burmese population [8]. This is the first study to correlate the gender and the number of canals in mandibular first molars in the South Indian population. The limitation of the study includes very small sample size and population studied. Also CBCT would always be a better assessment tool than periapical radiographs for root anatomical configuration studies [28].

With the advancements in caries prevention strategies several fluoridated toothpastes, mouthwashes as well as remineralizing agents are available $[20,26]$. Patients should be educated on the importance of the permanent mandibular first molar which is one of the earliest to erupt. During cleaning and shaping of root canal one must choose the instruments that preserve the cervical dentin thickness [28].

\section{Conclusion}

Within the limitations of the study the mandibular first molars mostly consisted of 3 canals in both male and female patients. Out of 712 male patients, $452(63.4 \%)$ had 3 canals and 244 $(34.2 \%)$ had 4 canals. Out of 588 female patients, $396(67.3 \%)$ had 3 canals and $173(29.4 \%)$ had 4 canals. The knowledge of root canal anatomy reduces the chance of missing a canal during root canal treatment. Also various anatomical intricacies of the root canal system such as fins, isthmuses and C- shaped canals are commonly seen in mandibular molars. Sufficient disinfection of the entire root canal system by use of irrigant activation and intra canal medicaments, helps in achieving long term success of root canal treatment.

\section{References}

[1]. Andreasen JO. Luxation of permanent teeth due to trauma. A clinical and radiographic follow-up study of 189 injured teeth. Scand J Dent Res. 1970;78(3):273-86. Pubmed PMID: 5273695.

[2]. Baba NZ, Goodacre CJ. Restoration of endodontically treated teeth: contemporary concepts and future perspectives. Endodontic Topics. 2014 Nov;31(1):68-83.

[3]. Baba NZ, White SN, Bogen G. Restoration of Endodontically Treated Teeth. InEndodontic Prognosis 2017 (pp. 161-192). Springer, Cham.

[4]. Berman LH, Hargreaves KM. Cohen's Pathways of the Pulp Expert Consult-E-Book. Elsevier Health Sciences; 2015 Sep 23

[5]. Chourasia HR, Meshram GK, Warhadpande M, Dakshindas D. Root canal 
morphology of mandibular first permanent molars in an Indian population. International journal of dentistry. 2012 Jan 1;2012.

[6]. Gupta A, Duhan J, Wadhwa J. Prevalence of Three Rooted Permanent Mandibular First Molars in Haryana (North Indian) Population. Contemp Clin Dent. 2017 Jan-Mar;8(1):38-41. Pubmed PMID: 28566849.

[7]. Floratos S, Vera J, Al-Malki F, Kim S. Inspection of the Resected Root Surface: Importance of Isthmus. Microsurgery in Endodontics. 2017 Sep 15:7382.

[8]. Gulabivala K, Aung TH, Alavi A, Ng YL. Root and canal morphology of Burmese mandibular molars. International endodontic journal. 2001 Jul;34(5):359-70.

[9]. Gutmann JL. C-Shaped Root Canal System. InThe Root Canal Anatomy in Permanent Dentition 2019 (pp. 255-274). Springer, Cham.

[10]. Hess W. Formation of root-canals in human teeth. The Journal of the National Dental Association. 1921 Sep 1;8(9):704-34.

[11]. Janani K, Palanivelu A, Sandhya R. Diagnostic accuracy of dental pulse oximeter with customized sensor holder, thermal test and electric pulp test for the evaluation of pulp vitality: an in vivo study. Brazilian Dental Science. 2020 Jan 31;23(1):8-p.

[12]. Jose J, Subbaiyan H. Different treatment modalities followed by dental practitioners for ellis class 2 fracture-A questionnaire-based survey. The Open Dentistry Journal. 2020 Feb 18;14(1).

[13]. Kantilieraki E, Delantoni A, Angelopoulos C, Beltes P. Evaluation of Root and Root Canal Morphology of Mandibular First and Second Molars in a Greek Population: A CBCT Study. Eur Endod J. 2019 Jul 18;4(2):62-68. Pubmed PMID: 32161889.

[14]. Khademi JA, Carr G, Schwartz RS, Trudeau M. Advanced cbct for endodontics: technical considerations, perception, and decision-making. Quintessence Publishing Company, Incorporated; 2017.

[15]. Kumar D, Antony SD. Calcified canal and negotiation-A review. Research Journal of Pharmacy and Technology. 2018 Aug 1;11(8):3727-30.

[16]. Manjunatha BS, Manjunatha BS. Textbook of dental anatomy and oral physiology. JP Medical Ltd; 2012 Nov 30.

[17]. Manohar MP, Sharma S. A survey of the knowledge, attitude, and awareness about the principal choice of intracanal medicaments among the general dental practitioners and nonendodontic specialists. Indian J Dent Res. 2018 Nov-Dec;29(6):716-720. Pubmed PMID: 30588997.

[18]. Nandini VV, Venkatesh V. Current concepts in the restoration of endodontically treated teeth. The Journal of Indian Prosthodontic Society. 2006 Apr 1;6(2):63.

[19]. Hussainy SN, Nasim I, Thomas T, Ranjan M. Clinical performance of resinmodified glass ionomer cement, flowable composite, and polyacid-modified resin composite in noncarious cervical lesions: One-year follow-up. Journal of conservative dentistry: JCD. 2018 Sep;21(5):510.

[20]. Nandakumar M, Nasim I. Comparative evaluation of grape seed and cranberry extracts in preventing enamel erosion: An optical emission spectrometric analysis. J Conserv Dent. 2018 Sep-Oct;21(5):516-520. Pubmed PMID: 30294113.

[21]. Nelson SJ. Wheeler's dental anatomy, physiology and occlusion-e-book. Elsevier Health Sciences; 2014 Sep 30.

[22]. Noor SS. Chlorhexidine: Its properties and effects. Research Journal of Pharmacy and Technology. 2016 Oct 1;9(10):1755.

[23]. de Pablo ÓV, Estevez R, Sánchez MP, Heilborn C, Cohenca N. Root anatomy and canal configuration of the permanent mandibular first molar: a systematic review. Journal of endodontics. 2010 Dec 1;36(12):1919-31.
[24]. Patel S, Brown J, Pimentel T, Kelly RD, Abella F, Durack C. Cone beam computed tomography in Endodontics - a review of the literature. Int Endod J. 2019 Aug;52(8):1138-1152. Pubmed PMID: 30868610.

[25]. Pineda F, Kuttler Y. Mesiodistal and buccolingual roentgenographic investigation of 7,275 root canals. Oral Surg Oral Med Oral Pathol. 1972 Jan;33(1):101-10. Pubmed PMID: 4500261.

[26]. Rajendran R, Kunjusankaran RN, Sandhya R, Anilkumar A, Santhosh R, Patil SR. Comparative evaluation of remineralizing potential of a paste containing bioactive glass and a topical cream containing casein phosphopeptide-amorphous calcium phosphate: An in vitro study. Pesquisa brasileira em odontopediatria e clinica integrada. 2019;19.

[27]. Ramamoorthi S, Nivedhitha MS, Divyanand MJ. Comparative evaluation of postoperative pain after using endodontic needle and EndoActivator during root canal irrigation: A randomised controlled trial. Australian Endodontic Journal. 2015 Aug;41(2):78-87.

[28]. Ramanathan S, Solete P. Cone-beam Computed Tomography Evaluation of Root Canal Preparation using Various Rotary Instruments: An in vitro Study. The journal of contemporary dental practice. 2015 Nov 1;16(11):869-72.

[29]. Teja KV, Ramesh S, Priya V. Regulation of matrix metalloproteinase-3 gene expression in inflammation: A molecular study. J Conserv Dent. 2018 NovDec;21(6):592-596. doi: 10.4103/JCD.JCD_154_18. PMID: 30546201.

[30]. Rashid AM, Suliman HA. Incidence of third root in mandibular permanent first molar: An endodontic challenge. Al-Rafidain Dental Journal. 2006 Jun $1 ; 6(2): 194-8$

[31]. Ravinthar K. Recent advancements in laminates and veneers in dentistry. Research Journal of Pharmacy and Technology. 2018 Feb 1;11(2):785-7.

[32]. Razumova S, Brago A, Barakat H, Howijieh A. Morphology of Root Canal System of Maxillary and Mandibular Molars. InHuman Teeth-Key Skills and Clinical Illustrations 2019 Oct 23. IntechOpen.

[33]. Rajakeerthi R, Nivedhitha MS. Natural Product as the Storage medium for an avulsed tooth-A Systematic Review. Cumhuriyet Dental Journal. 2019;22(2):249-56

[34]. Schilder H. Filling root canals in three dimensions. Dent Clin North Am. 1967 Nov:723-44.Pubmed PMID: 5262492.

[35]. Siddique R, Sureshbabu NM, Somasundaram J, Jacob B, Selvam D. Qualitative and quantitative analysis of precipitate formation following interaction of chlorhexidine with sodium hypochlorite, neem, and tulsi. J Conserv Dent. 2019 Jan-Feb;22(1):40-47. Pubmed PMID: 30820081.

[36]. Skidmore AE, Bjorndal AM. Root canal morphology of the human mandibular first molar. Oral Surg Oral Med Oral Pathol. 1971 Nov;32(5):778-84. doi: 10.1016/0030-4220(71)90304-5. Pubmed PMID: 5286234.

[37]. Teja KV, Ramesh S. Shape optimal and clean more. Saudi Endodontic Journal. 2019 Sep 1;9(3):235.

[38]. Versiani MA, Basrani B, Sousa-Neto MD, editors. The root canal anatomy in permanent dentition. Springer; 2018 Jul 25.

[39]. Vertucci FJ. Root canal anatomy of the human permanent teeth. Oral Surg Oral Med Oral Pathol. 1984 Nov;58(5):589-99. Pubmed PMID: 6595621.

[40]. Vertucci FJ, Williams RG. Furcation canals in the human mandibular first molar. Oral Surgery, Oral Medicine, Oral Pathology. 1974 Aug 1;38(2):30814.

[41]. Walker RT, Quackenbush LE. Three-rooted lower first permanent molars in Hong Kong Chinese. British Dental Journal. 1985 Nov;159(9):298-9.

[42]. Weine FS, Healey HJ, Gerstein H, Evanson L. Canal configuration in the mesiobuccal root of the maxillary first molar and its endodontic significance. 1969. J Endod. 2012 Oct;38(10):1305-8. Pubmed PMID: 2298016. 